\title{
On-site treatment of textile yarn dyeing effluents using an integrated biological-chemical oxidation process
}

\author{
A. M. Lotito - M. De Sanctis $\cdot$ S. Rossetti $\cdot$ \\ A. Lopez $\cdot$ C. Di Iaconi
}

Received: 3 September 2012/Revised: 11 February 2013/Accepted: 16 March 2013/Published online: 17 April 2013

(C) Islamic Azad University (IAU) 2013

\begin{abstract}
This paper reports the results of the treatment of a yarn dyeing effluent using an integrated biologicalchemical oxidation process. In particular, the biological unit was based on a sequencing batch biofilter granular sludge reactor (SBBGR), while the chemical treatment consisted of an ozonation step. Biological treatment alone was first performed as a reference for comparison. While biological treatment did not produce an effluent for direct discharge, the integrated process assured good treatment results, with satisfactory removal of chemical oxygen demand (up to $89.8 \%$ ), total nitrogen (up to $88.2 \%$ ), surfactants (up to $90.7 \%$ ) and colour (up to $99 \%$ ), with an ozone dose of $110 \mathrm{mg}$ of ozone per litre of wastewater. Biomass characterization by fluorescence in situ hybridization has revealed that filamentous bacteria represented about $20 \%$ of biomass (coherently with high sludge volume index values); thanks to its special design, SBBGR guaranteed, however, stable treatment performances and low effluent suspended solids concentrations, while conventional activated sludge systems suffer from sludge bulking and even treatment failure in such a condition. Furthermore, biomass characterization has evidenced the presence of a shortcut nitrification-denitrification process.
\end{abstract}

A. M. Lotito

Department of Water Engineering and Chemistry,

Politecnico di Bari, via Orabona 4, 70125 Bari, Italy

M. De Sanctis · A. Lopez · C. Di Iaconi $(\bowtie)$

Water Research Institute, National Research Council,

viale De Blasio 5, 70132 Bari, Italy

e-mail: claudio.diiaconi@ba.irsa.cnr.it

S. Rossetti

Water Research Institute, National Research Council, via Salaria km 29.300, C. P. 10, 00015 Monterotondo St. (RM), Italy
Keywords Yarn dyeing wastewater - Biological treatment - Ozonation - Integrated treatment . Biomass characterization

\section{Introduction}

Textiles and wearing apparel represent an important economic sector in Europe, accounting for about $3.6 \%$ of the EU-27 manufacturing in terms of value added and $6.3 \%$ in terms of employment in 2008 (European Commission 2011). Even if textile industry activities are distributed across Europe, they are mainly concentrated in few countries, among which Italy is the leading producer, with a turnover of about 60 billion $€(25$ billion $€$ for textile manufacturing) against about 170 billion $€$ from all EU-27 in 2008 (Eurostat data).

The textile industry is a water-intensive sector (consuming about 100-200 L of high-quality water per $\mathrm{kg}$ of textile product) and is rated as the most polluting among all industrial activities (considering both discharged volume and effluent composition) (Andleeb et al. 2010; Bechtold et al. 2004; Chen et al. 2011; Grekova-Vasileva and Topalova 2009; Tehrani-Bagha et al. 2010; Vandevivere et al. 1998). Water is used for cleaning the raw material and for many flushing steps during the whole production; furthermore, water is used as solvent in many dyeing baths.

Textile processing involves many steps, which differ as a function of the processed fibres (European Commission 2003). Basically, for making a fabric, a source of fibre from which a yarn can be made is required. The yarn is then processed by knitting or weaving, which turns the yarn into fabric. The yarn can be coloured before or after the conversion in fabric. According to this step, the textile processing may be classified into four categories, namely 
woven fabric dyeing, knitted fabric dyeing, yarn dyeing and printing.

A final wastewater is usually discharged, mixing the effluents from the various processing steps: its characteristics are the result of a complex combination of different factors, ranging from the type of fibres (raw materials), to the processed make-ups (fabrics), to the applied techniques (machineries), and to the types of chemicals and auxiliaries adopted (recipes) (Correia et al. 1994; European Commission 2003). Furthermore, it is possible to distinguish between cooling water (characterized by medium-high temperature, but low pollutant content), process water (consisting in various streams with different degrees of organic and inorganic compounds, ranging from those with high organic loads due to sizing agents and surfactants to dye-containing streams with a relatively lower organic load, high colour and high inorganic salt content) and washing water (with high flow rate and significant pollutant content) (Libra and Sosath 2003; Marcucci et al. 2003). As a consequence, wastewater characteristics in terms of strength and composition vary as a function of the different types of industrial processing systems and of the immense range of materials and chemicals (dyes, process aids and finishing products) involved in each industrial category (Buckley 1992; Correia et al. 1994; Vandevivere et al. 1998). Moreover, it is difficult to define a typical textile effluent even within the same subcategory, as the structure of textile industries varies widely from one industrial application to the other (Gemirli Babuna et al. 1998). Nevertheless, the main pollution load in textile industry usually comes from dyeing and finishing processes.

The complexity of textile effluents makes it difficult to treat them economically as they contain chelating agents, surfactants, thickeners, enzymes, detergents, grease, dirt, sizing agents, solvents, different additives, oxidizing and reducing agents, heavy metals and residual dyes (Arafat 2007; Badani et al. 2005; Buitron et al. 2004; Haroun and Idris 2009; Hassan and Hawkyard 2002; Lau and Ismail 2009; Nandy et al. 2005). A large fraction of chemicals includes toxicants, inhibitory compounds and recalcitrant organics with complex structures, such as aromatic rings, resistant to biodegradation (Grekova-Vasileva and Topalova 2009). Therefore, the search of effective treatments is one of the most demanding challenges in textile industry.

Biological methods (mainly based on conventional activated sludge systems) are widely applied, but they are not adequate enough for the efficient removal of colour, recalcitrant pollutants and surfactants present in textile effluents, neither as on-site nor as a centralized treatment (Vandevivere et al. 1998). Therefore, a combination of biological and physicochemical methods (such as coagulation-flocculation, activated carbon adsorption, filtration, chemical oxidation) is usually required for an effective treatment. Chemical oxidation is, however, the only technique able to remove the dyes intentionally designed to resist degradation since the other physicochemical methods only transfer the pollutants from one phase to another (hence, the disposal of residues is still a problem).

Due to its high reactivity with many dyes used in textile processing, ozone is the mostly used chemical oxidant for textile wastewater treatment (Alaton et al. 2002). Ozonation, however, can be used to mineralize such pollutants (i.e., as an end treatment) or to partially oxidize them into biodegradable intermediates (i.e., as treatment integrated with biological degradation). The latter application is particularly interesting as it permits to achieve some advantages, such as the reduction of the ozone dose, thus lowering treatment costs. However, in such an instance, a high synergistic effect with the biological stage is required for giving a considerable cost advantage.

In this paper, an integrated chemical (based on ozonation) and biological (based on a sequencing batch biofilter granular reactor-SBBGR) process, which assures a high synergy between biological and chemical oxidation, is proposed for treating the effluent from a yarn dyeing factory. The experimentation was carried out at Water Research Institute of Bari (Italy) in 2010-2011.

Results achieved through biological treatment alone (period A) and through the integrated one (period B) were compared to better observe the beneficial effect of chemical oxidation. The effect of ozone integration on microbial composition of SBBGR biomass was also monitored by fluorescence in situ hybridization (FISH). Sludge settling properties have been scrutinized as well, in order to demonstrate how SBBGR is able to assure stable results even with a biomass with poor properties, which usually leads to treatment failure in conventional activated sludge systems.

\section{Materials and methods}

Experimental setup and cycle configuration

The lab-scale reactor consisted of a biological SBBGR unit connected to an ozone column. The system was completely automated and controlled by a programmable logic controller (PLC).

The SBBGR was made up of a Plexiglas cylinder $(1 \mathrm{~m}$ height, $0.19 \mathrm{~m}$ internal diameter) filled at the bottom with a plastic support material (KMT-k1 Kaldnes, Norway; $10 \mathrm{~mm}$ diameter, $7 \mathrm{~mm}$ height, $630 \mathrm{~m}^{2} / \mathrm{m}^{3}$ specific surface, $950 \mathrm{~kg} / \mathrm{m}^{3}$ density, 0.75 porosity) kept between two sieves, to constitute the microbial bed (volume of about $14 \mathrm{~L}$ ). Head loss at the bottom of the bed was monitored every day to perform a washing step of the filter with compressed air whenever it exceeded an established threshold $(3 \mathrm{~m})$. 
The operation of SBBGR was based on 8-h treatment cycles, each consisting of three consecutive phases, namely filling, biological degradation and drawing (Fig. 1a). During the non-aerated filling phase, the influent was added from the bottom (up-flow operation) using a peristaltic pump (flow rate of $60 \mathrm{~L} / \mathrm{h}$ ). Then, in the biological degradation phase, the liquid in SBBGR was continuously aerated using two aerators in the liquid phase over the bed (total flux of $300 \mathrm{NL} / \mathrm{h}$ ), with the exception of the first hour of cycle, during which the aeration remained switched off to permit oxidized nitrogen removal; a continuous recycle through the microbial bed (via an external loop; $90 \mathrm{~L} / \mathrm{h}$ ) provided dissolved oxygen to biomass and assured substrate distribution. Finally, the treated effluent was drawn by gravity from a port located in the liquid phase over the bed through the opening of the motorized valve $(15 \mathrm{~min})$.

During the period in which integrated ozone treatment was performed, the SBBGR cycle was modified to include a fourth 30-min phase ("integrated biological degradation and ozonation" phase) before the drawing one to remove recalcitrant pollutants and colour (Fig. 1b). During this phase, the liquid in SBBGR was recirculated both through microbial bed and ozone reactor (volume $5 \mathrm{~L}$; height $90 \mathrm{~cm}$ ) using a peristaltic pump (flow rate of $70 \mathrm{~L} / \mathrm{h}$ ). Ozone was produced from pure oxygen by an ozone generator Modular $8 \mathrm{HC}-\mathrm{WEDECO}$ with maximum $\mathrm{O}_{3}$ production capacity of $8 \mathrm{~g} / \mathrm{h}$. The oxygen-ozone mixture was fed to the bottom part of the column by means of a porous plate, which enabled good gas break-up and enhanced liquid-gas contact. The ozone reactor was supplied with a residual ozone destroyer and ozone meter. Ozone concentration in the gas stream at the inlet and outlet of the ozone reactor was measured by a UV analyzer (ozone analyzer BMT 964, WEDECO, Germany). The transferred ozone was computed as the integral of the difference between the produced ozone and the residual ozone measured during the treatment; then, the ratio between such a value and the influent volume was indicated as the transferred ozone dose.
Analytical methods

Treatment performance was evaluated by measuring several parameters of influent and effluent, usually two or three times per week.

Chemical oxygen demand (COD), biochemical oxygen demand $\left(\mathrm{BOD}_{5}\right)$, total and volatile suspended solids (TSS and VSS), total Kjeldahl nitrogen (TKN), ammonia (N$\mathrm{NH}_{4}{ }^{+}$), total phosphorous (P) and $\mathrm{pH}$ were determined using standard methods (APHA 1998). Total surfactants were calculated by summing anionic [MBAS (methylene blue active substances); APHA 1998], non-ionic (LCK 333 of Dr. Lange; DEV H23) and cationic (LCK 331 of Dr. Lange; DEV H20) surfactants.

Total nitrogen (TN) was measured by means of a carbon analyzer (model 5050) with an additional total nitrogen measuring unit (model TNM-1) by Shimadzu Co Japan. Oxidized nitrogen $\left(\mathrm{N}-\mathrm{NO}_{\mathrm{x}}\right)$ was calculated as the difference between TN and TKN.

Colour removal was evaluated as decolourization percentage, measuring the absorbance of the samples in quartz cuvettes with a $1 \mathrm{~cm}$ path-length at three wavelengths (426, 558 and $660 \mathrm{~nm}$ ).

The specific excess sludge production was computed by dividing the TSS coming out of the reactor (effluent, washing operation, microbial samples and sludge accumulation in the bed) by the amount of COD removed in the same period.

Biomass concentration in the reactor was determined twice (at the end of periods $\mathrm{A}$ and $\mathrm{B}$, respectively), detaching representative samples of biomass (microbial samples) from three heights of the microbial bed (top, medium and bottom). The sampled bed volume was evaluated by counting the carrier elements $\left(n_{\text {carriers }}\right)$ and relating them to the number of carrier elements per litre of bed $(1,023)$. The sludge present on the removed carriers was collected in a known volume of tap water ( $\left.V_{\text {sludge }}\right)$, and TSS and VSS were measured. Sludge concentration in the
Fig. 1 Treatment cycle sketch of: a SBBGR (period A of experimentation), b SBBGR integrated with ozonation (period B of experimentation)
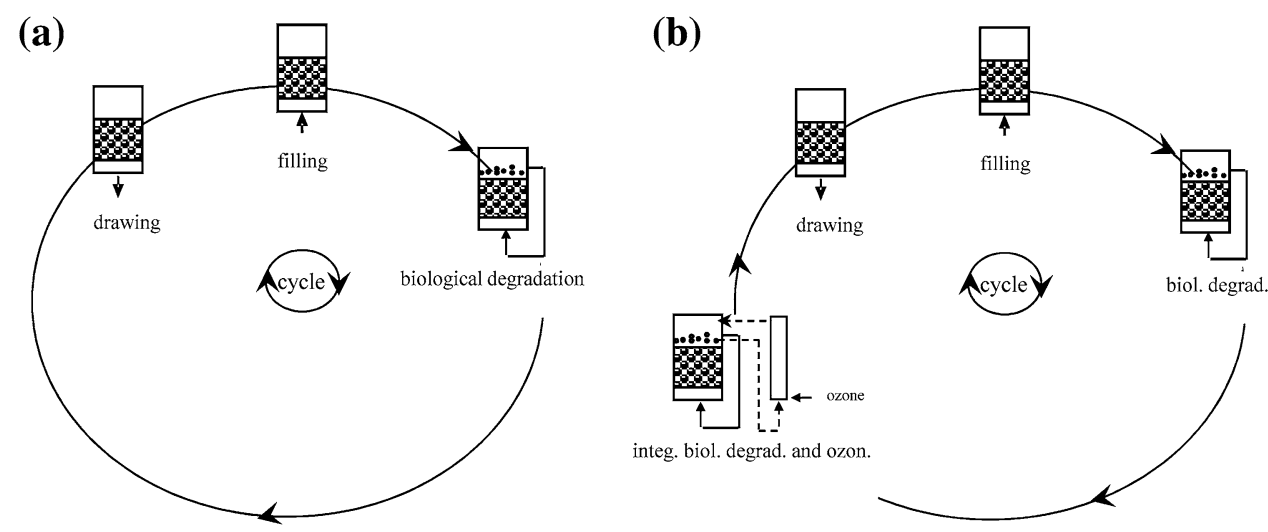
reactor bed could be then calculated according to the following formula:

$$
\begin{aligned}
& \text { Biomass TSS concentration }\left[\mathrm{g}_{\mathrm{TSS}} / \mathrm{L}_{\mathrm{bed}}\right] \\
& =\frac{\mathrm{TSS}[\mathrm{g} / \mathrm{L}] \cdot V_{\text {sludge }}[\mathrm{L}]}{\frac{n_{\text {carriers }}}{1023}}
\end{aligned}
$$

The ability of sludge to settle was evaluated by recording the position of the solid-liquid separation interface in a graduated cylinder of 1 or $0.5 \mathrm{~L}$, depending on the available volume of sludge, without stirring. Sludge settleability was defined in terms of sludge volume index (SVI), i.e. the volume occupied by the unit of mass of sludge after $30 \mathrm{~min}$ of settling.

Finally, biomass samples were analysed by FISH to define the relative abundance of the main microbial components. FISH analysis was performed on biomass samples fixed in formaldehyde ( $2 \%$ final concentration) and ethanol (48\% final concentration), according to the procedure described in Amann et al. (1995). Oligonucleotide probes specific for Alpha-, Beta-, Gamma- and Delta-proteobacteria (ALF968, Bet-42a, Gam-42a and Delta495mix probes, respectively), Flavobacteria (CF319a probe), Actinobacteria (HGC69A), Firmicutes (LGC354mix), Chloroflexi (CFX1223), TM7 division (TM7905), Planctomycetes (Pla46), Thauera/Azoarcus group (THAU646 and AZO644), Alcaligenes-Bordetella (ALBO577) and Archaea (ARC915) were used. Ammonia (Nso1225 probe) and nitrite oxidizing bacteria (Ntspa662 and NIT3 probes) were also monitored by FISH. All the hybridizations with group specific probes were carried out simultaneously with probes EUB338, EUB338-II and EUB338-III combined in a mixture (EUB338mix) for the detection of most bacteria and with DAPI staining for quantifying the total number of cells as described in De Sanctis et al. (2010). Details on oligonucleotide probes are available at probeBase (Loy et al. 2007). All the probes were synthesized with 5'-FITC and -Cy3 labels and purchased from MWG AG Biotech (Germany). Slides were examined under an epifluorescence microscope (Olympus BX51). All microscopic analyses were performed on biomass samples mechanically disaggregated by vortexing for few minutes with glass beads.

\section{Wastewater origin}

Wastewater was collected from the equalization tank of a yarn dyeing factory located in the textile district of Como (Italy) and provided in stocks of $1 \mathrm{~m}^{3}$. The factory processing steps are described in Fig. 2.

Operational schedule

Before starting the experiments with the yarn dyeing wastewater, the reactor had treated a fabric dyeing wastewater biologically for 200 days (Lotito et al. 2012) and through the integrated treatment for 60 days. When experiments with the yarn dyeing wastewater were started, average biomass concentration was about $26.4 \mathrm{gTSS} / \mathrm{L}_{\text {bed }}$.

After the acclimatization period, which lasted 2 months, the experimentation was arranged in two main periods: during the first one (period A, 50 days) only biological treatment was performed, while, during the second period (period B, 50 days), ozonation was integrated (see Fig. 1). Periods A and B were characterized by the same hydraulic load (i.e., $25 \mathrm{~L} /$ day). Period B was split in two runs (B1 and B2) characterized by a different transferred ozone dose (i.e., 55 and $110 \mathrm{mg}$ of ozone per litre of wastewater fed, respectively).

\section{Results and discussion}

\section{Treatment performance}

Influent and effluent concentrations of the main analysed parameters measured throughout periods A and B, together with removal percentages, are reported in Table 1 in terms of average values and value ranges.

TSS effluent concentrations were always below $35 \mathrm{mg} / \mathrm{l}$ with removal efficiency higher than $80 \%$. An increase of the removal efficiency was recorded when SBBGR was integrated with ozonation, with a consequent reduction of effluent residual concentration. This can be attributed to the ability of ozone treatment to remove some inhibiting compounds, thus improving the biomass aggregation in SBBGR with a consequent increase in filtering capacity. This hypothesis is supported by the increase in biomass concentration (from 29.2 gTSS/L $\mathrm{L}_{\text {bed }}$ at the end of period A up to $37.6 \mathrm{gTSS} / \mathrm{L}_{\text {bed }}$ at the end of period B) and in head loss.

COD removal efficiencies in the range 63.6-78.5\% were achieved during biological treatment alone (period A) with residual concentrations in the effluent (in the range 142-250 mg/l) almost always above the Italian discharge limit of $160 \mathrm{mg} / \mathrm{l}$. This limited removal efficiency must be ascribed to the presence in the textile wastewater of a fraction of recalcitrant pollutants, as proved by the low $\mathrm{BOD}_{5} / \mathrm{COD}$ ratio values of the influent (see Table 1) and confirmed also by the complete removal of biodegradable compounds (in fact, $\mathrm{BOD}_{5}$ value in the effluent was close to zero).

After ozone integration (period B), stable effluent COD values always below the limits for direct discharge were achieved. In particular, effluent COD concentrations and removal efficiencies in the range $152-160 \mathrm{mg} / \mathrm{l}$ and 78.5-84.3\%, respectively, were obtained using a transferred ozone dose of $55 \mathrm{mgO}_{3} / \mathrm{L}_{\text {inf }}$ (run B1). As expected, 


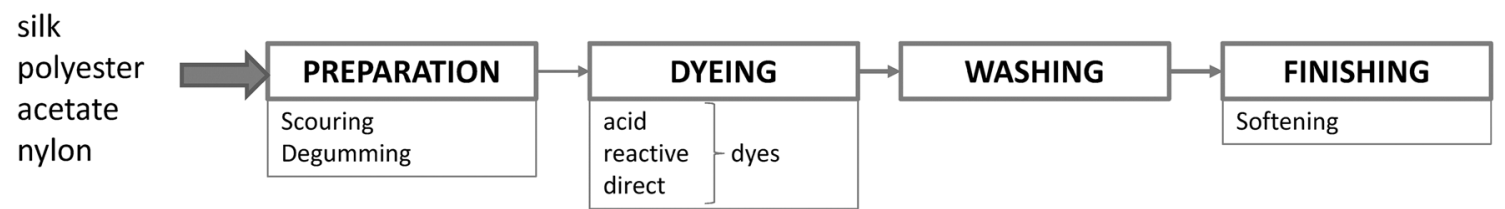

Fig. 2 Block diagram of the yarn dyeing factory. The produced wastewater results from mixing the effluents of the different processing steps

Table 1 Influent and effluent concentrations, and removal efficiencies of the main parameters (in terms of average values and value ranges) investigated throughout experimentation

\begin{tabular}{|c|c|c|c|c|c|c|}
\hline \multirow[t]{4}{*}{ Parameter } & \multicolumn{6}{|l|}{ Period } \\
\hline & \multirow{2}{*}{\multicolumn{2}{|c|}{ A }} & \multicolumn{4}{|l|}{ B } \\
\hline & & & \multicolumn{2}{|l|}{ B1 } & \multicolumn{2}{|l|}{ B2 } \\
\hline & Mean & Value range & Mean & Value range & Mean & Value range \\
\hline \multicolumn{7}{|l|}{ TSS } \\
\hline Influent (mg/l) & 95 & $42-159$ & 136 & $102-159$ & 102 & $61-134$ \\
\hline Effluent (mg/l) & 18 & $8-34$ & 9 & $6-15$ & 12 & $9-15$ \\
\hline Removal (\%) & 80.1 & $56.9-87.6$ & 92.3 & $85.3-96.1$ & 87.2 & $80.8-93.2$ \\
\hline \multicolumn{7}{|l|}{ COD } \\
\hline Influent (mg/l) & 760 & $550-960$ & 892 & $708-1060$ & 723 & $450-980$ \\
\hline Effluent (mg/l) & 211 & $142-250$ & 158 & $152-160$ & 117 & $98-135$ \\
\hline Removal (\%) & 72.9 & $63.6-78.5$ & 81.9 & $78.5-84.3$ & 82.4 & $71.8-89.8$ \\
\hline \multicolumn{7}{|l|}{$\mathrm{BOD}_{5}$} \\
\hline Influent (mg/l) & 232 & $179-284$ & 272 & 194-384 & 222 & $198-354$ \\
\hline Effluent (mg/l) & 14 & $13-15$ & 8 & $6-14$ & 6 & $2-8$ \\
\hline Removal (\%) & 93.5 & $91.6-95.4$ & 96.4 & $96.1-96.8$ & 97.8 & $97.4-98.1$ \\
\hline \multicolumn{7}{|l|}{$\mathrm{TN}$} \\
\hline Influent (mg/l) & 27.1 & $21.2-32.3$ & 19.6 & $19.0-21.2$ & 29.9 & $28.0-34.1$ \\
\hline Effluent (mg/l) & 11.9 & $3.4-23.7$ & 6.9 & $7.1-8.2$ & 7.9 & $5.2-13.1$ \\
\hline Removal (\%) & 54.9 & $29.2-85.8$ & 72.2 & $64.6-83.5$ & 75.9 & $57.1-88.2$ \\
\hline \multicolumn{7}{|l|}{$\mathrm{N}-\mathrm{NO}_{\mathrm{x}}^{-}$} \\
\hline Influent (mg/l) & 0.4 & $0.2-0.5$ & 1.45 & $0.9-1.6$ & 0.3 & $0.2-0.8$ \\
\hline Effluent (mg/l) & 0.6 & $0.4-1.1$ & 0.7 & $0.6-0.9$ & 1.5 & $0.8-1.9$ \\
\hline \multicolumn{7}{|l|}{ Total surfactants } \\
\hline Influent (mg/l) & 36.5 & $27.2-43.6$ & 39.8 & $33.0-50.1$ & 24.1 & $22.3-29.2$ \\
\hline Effluent (mg/l) & 7.6 & $5.0-12.7$ & 6.5 & $5.9-7.3$ & 2.7 & $2.2-3.4$ \\
\hline Removal (\%) & 78.9 & $70.1-87.8$ & 82.9 & $77.8-87.2$ & 90.2 & $90.1-90.7$ \\
\hline \multicolumn{7}{|l|}{ Colour $426 \mathrm{~nm}$} \\
\hline Influent (Abs) & 0.083 & $0.065-0.111$ & 0.349 & $0.261-0.468$ & 0.153 & $0.082-0.277$ \\
\hline Effluent (Abs) & 0.070 & $0.049-0.088$ & 0.040 & $0.035-0.047$ & 0.014 & $0.001-0.028$ \\
\hline Removal (\%) & 15.1 & $0-38.7$ & 88.0 & $85.1-91.4$ & 90.1 & 87.9-99.0 \\
\hline \multicolumn{7}{|l|}{ Colour $558 \mathrm{~nm}$} \\
\hline Influent (Abs) & 0.039 & $0.028-0.057$ & 0.172 & $0.123-0.248$ & 0.069 & $0.034-0.124$ \\
\hline Effluent (Abs) & 0.032 & $0.022-0.045$ & 0.016 & $0.012-0.019$ & 0.004 & $0.003-0.007$ \\
\hline Removal (\%) & 14.9 & $0-34.7$ & 90.0 & $87.0-92.3$ & 92.2 & 88.6-96.8 \\
\hline \multicolumn{7}{|l|}{ Colour $660 \mathrm{~nm}$} \\
\hline Influent (Abs) & 0.022 & $0.016-0.034$ & 0.079 & $0.053-0.118$ & 0.038 & $0.018-0.066$ \\
\hline Effluent (Abs) & 0.018 & $0.012-0.031$ & 0.007 & $0.005-0.009$ & 0.002 & $0.001-0.004$ \\
\hline Removal (\%) & 20.8 & $0-40.7$ & 90.4 & $86.6-93.2$ & 93.2 & $85.6-98.5$ \\
\hline
\end{tabular}


by doubling the transferred ozone dose (run B2), the COD removal efficiency increased up to $82.4 \%$ on average, with residual concentrations in the range $98-135 \mathrm{mg} / \mathrm{l}$.

Assuming that the effluent COD of period A (biological treatment alone) was made of recalcitrant compounds, an average value of the ratio between the transferred ozone dose and the removed recalcitrant COD of about 1 is obtained in both runs of period B. This value is much lower than those reported in the literature in the treatment of the same type of wastewater. In fact, Dogruel et al. (2002) found a value higher than 6.5 during the ozonation of a cotton finishing textile effluent. Libra and Sosath (2003) reported a value as high as 6 [expressed in terms of DOC (dissolved organic carbon) removed] to meet direct discharge standards for the treatment of a dye-bath wastewater coming from a textile finishing mill by combining biological treatment and ozonation. Finally, Orhon et al. (2002) obtained values higher than 2 for treating wastewater from a cotton and synthetic fabrics mill by post ozonation after biological treatment.

The effect of ozone on removal efficiencies is clearly evident in Fig. 3, which shows the COD concentration profiles during a typical treatment cycle in runs B1 and B2. In fact, looking at these profiles, it is possible to distinguish three consecutive trends: in the first part of the profiles, readily biodegradable pollutant removal occurs; then, biological treatment is almost completed; finally, the third portion, which coincides with the "integrated biological degradation and ozonation" phase, highlights the benefits produced by ozone.

TN removal values were quite sparse during period A, ranging from 29.2 to $85.8 \%$, even if effluent concentrations were mostly below $15 \mathrm{mg} / \mathrm{l}$ (on average $11.9 \mathrm{mg} / \mathrm{l}$ ). The lowest TN removal efficiency values were recorded, however, with the same wastewater stock, indicating the

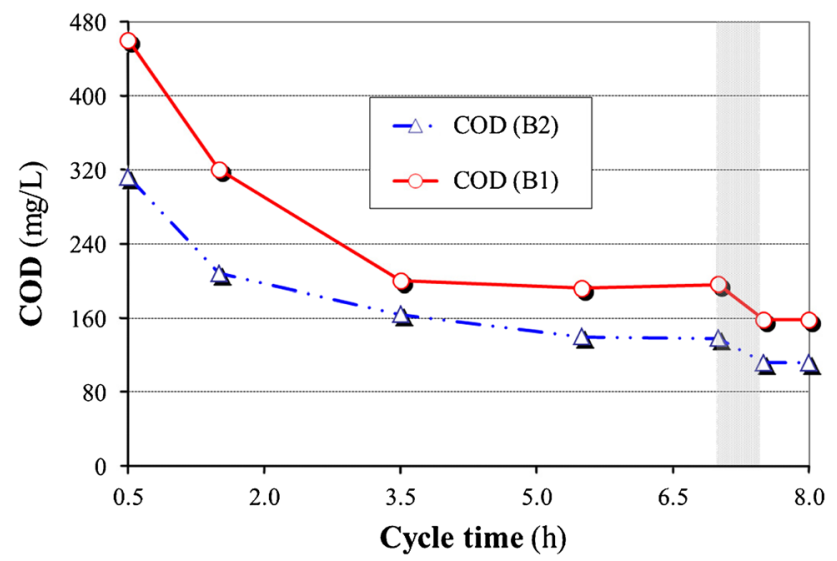

Fig. 3 Bulk COD concentrations within a typical treatment cycle of runs $\mathrm{B} 1$ and $\mathrm{B} 2$. The value 0.5 on the $x$ axis corresponds to the end of the filling phase presence of inhibition phenomena of the nitrification process due to certain pollutants. Taking into account the nitrogen request for biomass growth (i.e., about $5.0 \mathrm{mgN} /$ gCODremoved), calculated by multiplying sludge production $(0.10 \mathrm{kgTSS} / \mathrm{kgCOD}$ removed; see below) by measured nitrogen biomass content ( $0.05 \mathrm{gN} / \mathrm{gTSS})$, less than $4 \mathrm{mg} / \mathrm{l}$ of TN were needed for the observed COD removal. Therefore, nitrogen balance clearly shows that $\mathrm{TN}$ was removed mostly by a simultaneous nitrification-denitrification process (as a final anoxic phase for denitrification was not planned in the treatment cycle). The very low oxidized nitrogen concentrations in the effluent (i.e., lower than $1 \mathrm{mg} / \mathrm{l}$ ) confirm the presence of such a process, which can be ascribed to the high biomass concentration recorded in SBBGR bed (i.e., on average, $29.2 \mathrm{gTSS} / \mathrm{L}_{\text {bed }}$; VSS/ TSS: 0.85 ) and to the transient conditions (typical of sequential reactors) that generate contiguous anoxic and aerobic biomass layers.

After ozone integration (period B), TN removal efficiency increased, on average, up to $75.9 \%$ (with the highest transferred ozone dose) and became more stable (see "value range" column of Table 1), thus demonstrating the benefits produced by chemical oxidation in removing the compounds that can inhibit the nitrification process.

Significant removal of total surfactants was achieved in period A (in the range 70.1-87.8\%); nevertheless, effluent concentrations were still high, with peaks even above $10 \mathrm{mg} / \mathrm{l}$. Ozone integration improved surfactant removal, with final effluent concentrations of 6.5 and $2.7 \mathrm{mg} / \mathrm{l}$ on average during runs $\mathrm{B} 1$ and $\mathrm{B} 2$, respectively.

Colour removal for the three analysed wavelengths was rather sparse and strongly dependent on influent composition $(0-40 \%)$ during period A. On the contrary, good results were obtained after ozone integration with removal efficiencies always higher than $85 \%$ and final effluent colour sufficiently low to allow direct discharge (i.e., colour was not visible after a 20 -fold dilution of the sample, according to the current regulation). The effects of ozone are well highlighted in Fig. 4, which shows the colour removal trend within a typical treatment cycle; in fact, looking at these profiles, it is possible to observe a sharp increase of colour removal at any wavelength during the "integrated biological degradation and ozonation" phase.

Finally, sludge production was $0.10 \mathrm{kgTSS} / \mathrm{kgCO}-$ $\mathrm{D}_{\text {removed }}$ for period A and $0.15 \mathrm{kgTSS} / \mathrm{kgCOD} \mathrm{D}_{\text {removed }}$ for period $\mathrm{B}$, lower than the value of $0.4-0.6 \mathrm{kgVSS} / \mathrm{kgCO}$ $\mathrm{D}_{\text {removed }}$ typical of conventional activated sludge systems (Khursheed and Kazmi 2011).

Biomass characterization

As reported in "Materials and methods", biomass samples were drawn from three bed depths (top, medium and 


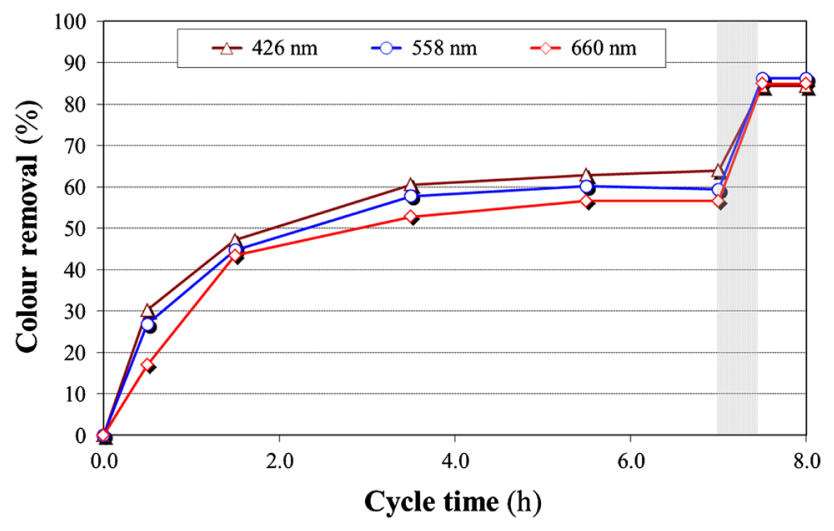

Fig. 4 Colour removal (at 426, 558 and $660 \mathrm{~nm}$ ) in a typical treatment cycle of run B2. The shadowed area individuates the "integrated biological degradation and ozonation" phase

bottom) at the end of both experimental periods (i.e., periods A and B) to evaluate sludge concentration, settling properties and microbial composition.

Starting from an initial value of about $26.4 \mathrm{gTSS} / \mathrm{L}_{\text {bed }}$, the biomass concentration in the reactor increased to $29.2 \mathrm{gTSS} / \mathrm{L}_{\text {bed }}$ at the end of period A and $37.6 \mathrm{gTSS} / \mathrm{L}_{\text {bed }}$ at the end of period B. Owing to the up-flow operation of the reactor, a stratified distribution was noticed: biomass concentration was $24.3,30.9$ and $32.5 \mathrm{gTSS} / \mathrm{L}_{\text {bed }}$ at the end of period A and 29.8, 36.6 and $46.3 \mathrm{gTSS} / \mathrm{L}_{\mathrm{bed}}$ at the end of period $\mathrm{B}$ at top, medium and bottom position in the bed, respectively.

Bacteria represented the main microbial components of the biomass, with relative abundances ranging between 55 and $73 \%$ of the total biomass (expressed as the percentage of bacteria highlighted by FISH over total DAPI stained cells; Fig. 5). A slightly lower ratio bacteria/total cells was observed after the introduction of ozone (period B) probably due to the increase of biomass concentration, which led to a reduction of the sludge organic load applied to biomass and, consequently, to a moderate reduction of the overall microbial activity. Negligible differences were found among samples under the same operating conditions (Fig. 5).

The detailed bacterial composition was elucidated by applying FISH probes with higher specificity. The analysis allowed identifying most bacteria ( $\geq 90 \%$ of total bacteria) in all the screened samples (Fig. 5). No marked differences were observed among biomass samples taken at the three different reactor depths. Six bacterial phyla were generally present with a slight dominance of Flavobacteria, which increased during period B and represented about $20 \%$ of total biomass. Members of Flavobacteria are reported to be facultative anaerobic microorganisms; hence, their stable establishment and increase in the SBBGR biomass could be linked to the oxygen diffusion limitation in reactor bed caused by high biomass concentration.
A peculiarity of the SBBGR biomass was the occurrence of filamentous bacteria (about $20 \%$ of total biomass), which, differently from conventional activated sludge systems, did not negatively affect the quality of the final effluent. This finding is also consistent with previous studies carried out with SBBGR technology (De Sanctis et al. 2010; Di Iaconi et al. 2010). In particular, Gammaproteobacteria were almost totally constituted by the filamentous organism Thiothrix spp., whereas some Betaproteobacteria were identified as Sphaerotilus natans (Fig. 5). The latter filamentous bacterium is commonly reported to be able to grow under low DO conditions.

This result is somehow interesting since the sensitivity of microorganisms to several toxic compounds (like most commercial dyes) in conventional activated sludge process causes problems of sludge bulking, rising sludge and pin point flocs formation, which greatly affect global treatment performances (Ahn et al. 1999; Bes-Pià et al. 2002; Delee et al. 1998). The investigation of settling properties has shown that SBBGR sludge settleability, evaluated on microbial samples, was poor, as a sludge sample is considered to be easily settleable if SVI is below $80 \mathrm{~cm}^{3} / \mathrm{g}$ (values above $120 \mathrm{~cm}^{3} / \mathrm{g}$ indicate poor settleability). In fact, at the end of period A, SVI values were high, with an average of $150 \mathrm{~cm}^{3} / \mathrm{g}$. The stratified biomass concentration in the reactor was reflected also in a different settling behaviour in sludge samples taken from different heights of the microbial bed: SVI values ranged from $182.9 \mathrm{~cm}^{3} / \mathrm{g}$ for the top sample to $135.6 \mathrm{~cm}^{3} / \mathrm{g}$ for the medium sample, to $124.1 \mathrm{~cm}^{3} / \mathrm{g}$ for the bottom one. Despite ozone integration improved sludge settleability in period B, SVI values were still higher than $80 \mathrm{~cm}^{3} / \mathrm{g}$, with an average of $105 \mathrm{~cm}^{3} / \mathrm{g}$. In this case, SVI values ranged from $107.7 \mathrm{~cm}^{3} / \mathrm{g}$ for the top sample to $115.4 \mathrm{~cm}^{3} / \mathrm{g}$ for the medium sample, to $89.1 \mathrm{~cm}^{3} / \mathrm{g}$ for the bottom one. The low biomass settleability has to be ascribed to the development of the high fraction of filamentous bacteria observed by FISH. It is interesting to observe, however, that the poor biomass settleability did not affect at all the treatment performance, as demonstrated by stable removal efficiencies and by the very low effluent TSS concentrations; this result constitutes an important advantage of SBBGR over traditional activated sludge systems.

A deeper analysis of Betaproteobacteria revealed the presence of some ammonia oxidizing (lower than $1 \%$ of the total biomass) and denitrifying (about $4-6 \%$ of the total biomass) bacteria, in line with the evidence of simultaneous nitrification-denitrification recorded in the system. The presence of nitrite-oxidisers was also investigated, but no bacteria belonging to this functional group were found. This result suggests the oxidation of ammonium to nitrite (nitritation) followed by its reduction to nitrogen gas. The removal of ammonium over nitrite 
Fig. 5 Microbial composition of SBBGR biomass estimated by FISH at three different bed heights [top $(T)$, medium $(M)$ and bottom $(B)$ ]

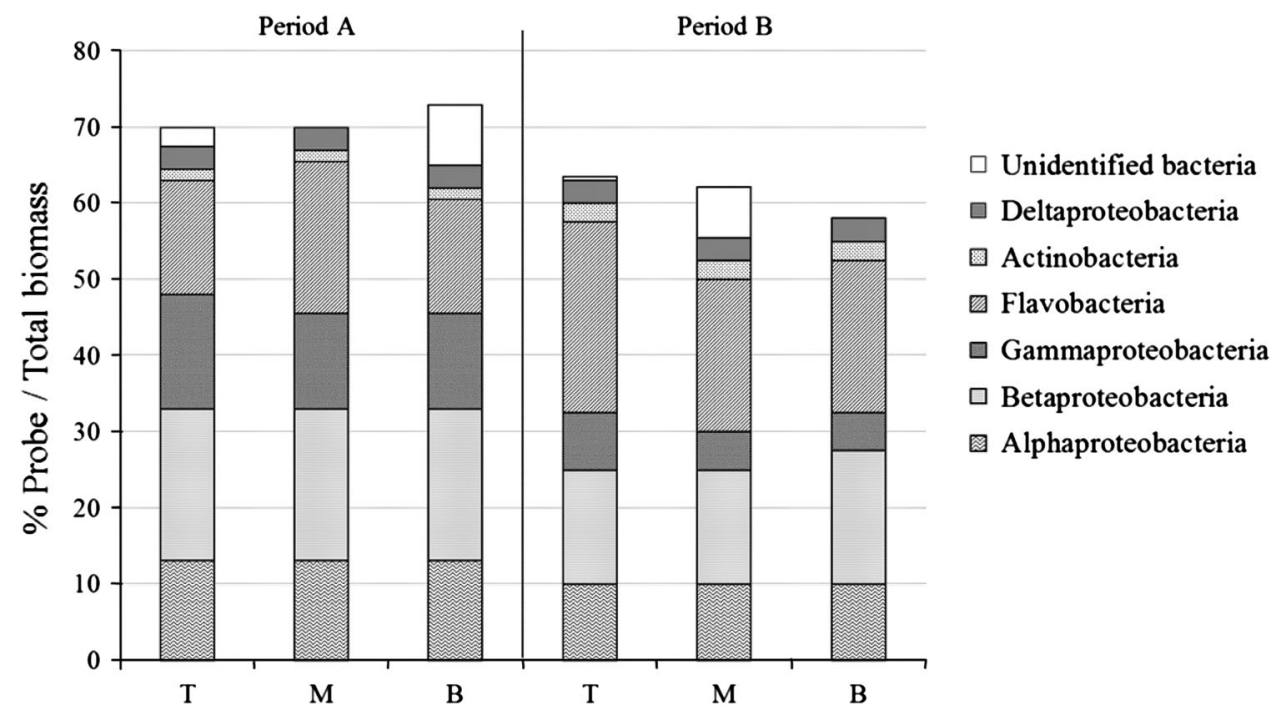

without passing by nitrate (i.e., the so-called shortcut nitrification-denitrification process) has received great attention by researchers thanks to the possibility to save up to $25 \%$ of oxygen and $40 \%$ of organic carbon source (Verstraete and Philips 1998). However, it is usually difficult to achieve a stable shortcut nitrification-denitrification at neutral $\mathrm{pH}$, ambient temperature and $\mathrm{DO}$ in the range $2-5 \mathrm{mg} / \mathrm{l}$ (Gao et al. 2009); in particular, a long aeration time can gradually convert a shortcut nitrification process into full nitrification. The high biomass concentration in SBBGR can be responsible for the disappearance of nitrite oxidizing bacteria (NOB). In fact, due to the high biomass concentration and to the oxygen diffusion gradient, micro-aerated, anoxic and even anaerobic zones exist in the reactor; such a condition can have inhibited NOB and caused their disappearance, because they are less robust than ammonia oxidizing bacteria (AOB) towards low DO, due to the difference in the saturation constant for oxygen (Sinha and Annachhatre 2007).

The existence of anaerobic zones due to the high biomass concentration is confirmed by the presence of $\mathrm{Ar}$ chaea, monitored by means of the general probe for this domain, in all screened samples, with an average value of 1 and $2 \%$ of total biomass during period $\mathrm{A}$ and $\mathrm{B}$, respectively.

Finally, due to certain features of the proposed process (low foot-print and modular design system), there are no obstacles to scale it up either for upgrading the existing treatment plants or in the case of new installations.

\section{Conclusion}

The integrated biological-chemical treatment performed in a SBBGR assured good results in the treatment of a yarn dyeing effluent, with COD, TN, surfactants and colour removals up to $89.8,88.2,90.7$ and $99 \%$, respectively.

The analysis of biomass composition by FISH has revealed the presence of a high fraction of filamentous bacteria $(20 \%)$, as confirmed by the poor sludge settleability (high SVI values). Despite the high contribution of filamentous bacteria, thanks to its special design SBBGR guaranteed stable performances and low effluent TSS ( $<35 \mathrm{mg} / \mathrm{l}$ with the biological treatment, $<15 \mathrm{mg} / \mathrm{l}$ with the integrated one), while activated sludge systems suffer from sludge bulking and even treatment failure in such a condition. Such a feature is important in the treatment of textile effluents as the presence of toxic and recalcitrant compounds often produces sludge bulking, rising sludge and pin point floc formation.

Another interesting result shown by FISH is the removal of nitrogen through a shortcut nitrification-denitrification process, which allows saving both oxygen and organic carbon in nitrogen removal: in fact, while both ammonia oxidizing and denitrifying bacteria were present, nitrite oxidizing bacteria were not detected. The high biomass concentration in the reactor can be responsible for the disappearance of NOB, due to the oxygen diffusion gradient, which results in the coexistence of micro-aerated, anoxic and even anaerobic zones in the microbial bed. The 
existence of anaerobic zones is confirmed by the presence of Archaea in all sludge samples.

Acknowledgments The study was financially supported by Lariana Depur s.p.a. (Grant of 31 August 2009), a company operating wastewater treatment plants in the textile industrial district of Como (Italy).

\section{References}

Ahn DH, Chang WS, Yoon TI (1999) Dyestuff wastewater treatment using chemical oxidation, physical adsorption and fixed bed biofilm process. Process Biochem 34:429-439

Alaton IA, Balcioglu IA, Bahnemann DW (2002) Advanced oxidation of a reactive dyebath effluent: comparison of $\mathrm{O}_{3}, \mathrm{H}_{2} \mathrm{O}_{2} / \mathrm{UV}-\mathrm{C}$ and $\mathrm{TiO}_{2} / \mathrm{UV}$-A processes. Water Res 36:1143-1154

Amann RI, Ludwig W, Schleifer K-H (1995) Phylogenetic identification and in situ detection of individual microbial cells without cultivation. Microbiol Mol Biol R 59:143-169

Andleeb S, Atiq N, Ali MI, Razi-ul-Hussnain R, Shafique M, Ahmad B, Ghumro PB, Hussain M, Hameed A, Ahmad S (2010) Biological treatment of textile effluent in stirred tank bioreactor. Int J Agr Biol 12:256-260

APHA, AWWA, WEF (1998) Standard Methods for the Examination of Water and Wastewater, 20th edn. American Public Health Association, American Water Works Association, Water Environment Federation, Washington, DC

Arafat HA (2007) Simple physical treatment for the reuse of wastewater from textile industry in the Middle East. J Environ Eng Sci 6:115-122

Badani Z, Ait-Amar H, Si-Salah A, Brik M, Fuchs W (2005) Treatment of textile waste water by membrane bioreactor and reuse. Desalination 185:411-417

Bechtold T, Burtscher E, Hung Y-T (2004) Treatment of textile wastes. In: Wang LK, Hung Y-T, Lo HH, Yapijakis C (eds) Handbook of industrial and hazardous wastes treatment, 2nd edn. Marcel Dekker Inc, New York, pp 379-414

Bes-Pià A, Mendoza-Roca JA, Alcaina-Miranda MI, Iborra-Clar A, Iborra-Clar MI (2002) Reuse of wastewater of the textile industry after its treatment with a combination of physicochemical treatment and membrane technologies. Desalination 149:169-174

Buckley CA (1992) Membrane technology for the treatment of dyehouse effluents. Water Sci Technol 25(10):203-209

Buitron G, Quezada M, Moreno G (2004) Aerobic degradation of the azo dye acid red 151 in a sequencing batch biofilter. Bioresour Technol 92:143-149

Chen G, Huang M, Chen L, Chen D (2011) Biotreatment of azo dyeing wastewater using a modified anaerobic-anoxic-aerobic reactor system. Adv Mat Res 183-185:170-175

Correia VM, Stephenson T, Judd SJ (1994) Characterisation of textile wastewaters-a review. Environ Technol 15:917-929

De Sanctis M, Di Iaconi C, Lopez A, Rossetti S (2010) Granular biomass structure and population dynamics in sequencing batch biofilter granular reactor (SBBGR). Bioresour Technol 101:2152-2158
Delee W, O’Neill C, Hawkes FR, Pinheiro HM (1998) Anaerobic treatment of textile effluents: a review. J Chem Technol Biotechnol 73:323-335

Di Iaconi C, Del Moro G, De Sanctis M, Rossetti S (2010) A chemically enhanced biological process for lowering operative costs and solid residues of industrial recalcitrant wastewater treatment. Water Res 44:3635-3644

Doğruel S, Germirli-Babuna F, Kabdaşli I, Insel G, Orhon D (2002) Effect of stream segregation on ozonation for the removal of significant COD fractions from textile wastewater. J Chem Technol Biotechnol 78:6-14

European Commission (2003) Integrated Pollution Prevention and Control (IPPC), Reference document on best available techniques for the textiles industry

European Commission (2011) Eurostat pocketbooks-key figures on european business with a special feature on SMEs. Publications Office of the European Union, Luxembourg

Gao D, Peng Y, Li B, Liang H (2009) Shortcut nitrificationdenitrification by real-time control strategies. Bioresour Technol 100:2298-2300

Gemirli Babuna F, Orhon D, Ubay Cokgor E, Insel G, Yaprakli B (1998) Modelling of activated sludge for textile wastewater. Water Sci Technol 38(4-5):9-17

Grekova-Vasileva M, Topalova Y (2009) Biological algorithms for textile wastewater management. Biotechnol Biotech Equip 23(2):442-447

Haroun M, Idris A (2009) Treatment of textile wastewater with an anaerobic fluidized bed reactor. Desalination 237:357-366

Hassan M, Hawkyard CJ (2002) Decolourisation of aqueous dyes by sequential oxidation treatment with ozone and Fenton's reagent. J Chem Technol Biotechnol 77:834-841

Khursheed A, Kazmi AA (2011) Retrospective of ecological approaches to excess sludge reduction. Water Res 45:4287-4310

Lau WJ, Ismail AF (2009) Polymeric nanofiltration membranes for textile dye wastewater treatment: preparation, performance evaluation, transport modelling and fouling control-a review. Desalination 245:321-348

Libra JA, Sosath F (2003) Combination of biological and chemical processes for the treatment of textile wastewater containing reactive dyes. J Chem Technol Biotechnol 78:1149-1156

Lotito AM, Fratino U, Mancini A, Bergna G, Di Iaconi C (2012) Effective aerobic granular sludge treatment of a real dyeing wastewater. Int Biodeterior Biodegrad 69:62-68

Loy A, Maixner F, Wagner M, Horn M (2007) ProbeBase-an online resource for rRNA-targeted oligonucleotide probes: new features 2007. Nucleic Acids Res 35:D800-D804

Marcucci M, Ciabatti I, Matteucci A, Vernaglione G (2003) Membrane technologies applied to textile wastewater treatment. Ann NY Acad Sci 984:53-64

Nandy T, Dhodapkar RS, Pophali GR, Kaul SN, Devotta S (2005) Application of chemical, biological and membrane separation processes in textile industry with recourse to zero effluent discharge — a case study. Environ Technol 26:1055-1063

Orhon D, Dulkadiroğlu H, Doğruel S, Kabdaşli I, Sozen S, Gemirli Babuna F (2002) Ozonation application in activated sludge systems for a textile mill effluent. Water Sci Technol 45(1-2):305-313

Sinha B, Annachhatre AP (2007) Partial nitrification-operational parameters and microorganisms involved. Rev Environ Sci Biotechnol 6:285-313 
Tehrani-Bagha AR, Mahamoodi NM, Menger FM (2010) Degradation of a persistent organic dye from colored textile wastewater by ozonation. Desalination 260:34-38

Vandevivere PC, Bianchi R, Verstraete W (1998) Treatment and reuse of wastewater from the textile wet-processing industry: review of emerging technologies. J Chem Technol Biotechnol 72:289-302

Verstraete W, Philips S (1998) Nitrification-denitrification processes and technologies in new contexts. Environ Pollut 102(S1):717-726 